\title{
LA DIFÍCIL ARTICULACIÓN DE UNA NUEVA INSTITUCIÓN: EL DÉFENSEUR DES DROITS FRANCÉS
}

\author{
ÁNGEL J. SÁNCHEZ NAVARRO \\ Profesor Titular de Derecho Constitucional \\ Universidad Complutense de Madrid
}

\author{
SUMARIO \\ I. Introducción: el Défenseur des droits en \\ la reforma constitucional de 2008. \\ II. Su difícil articulación.
}

III. A modo de conclusión.

\section{INTRODUCCIÓN: EL DÉFENSEUR DES DROITS EN LA REFORMA CONSTITUCIONAL DE 2008}

La última crónica sobre la "Actualidad política y constitucional francesa" publicada en esta Revista prestaba especial atención a la (entonces, recién aprobada) reforma constitucional para la "modernización de las instituciones de la V República" ". Decíamos allí, tras examinar someramente las circunstancias que la rodearon y los trabajos que la antecedieron, que esta reforma de la Constitución de 1958, la vigésima cuarta, tenía carácter global y estructural y era, sin duda, la de mayor calado desde que, en 1962, se estableció la elección del Presidente de la República mediante sufragio universal.

Recordábamos asimismo que, de acuerdo con la Exposición de motivos que acompañó al proyecto de ley, las modificaciones del texto constitucional se articulaban en torno a tres grandes líneas recíprocamente complementarias y que se sintetizaban en conseguir: «un poder ejecutivo mejor controlado, un Parlamento profundamente reforzado y nuevos derechos para los ciudadanos".

A caballo entre el primero y el último de estos objetivos se encuentra el "Defensor de los Derechos" [Défenseur des droits]. Como su propio nombre in-

1 TRC, núm. 22 (2008), págs. 453 y ss.; en especial, 458 a 462, acerca de la Loi constitutionnelle n. ${ }^{\circ}$ 2008-724 du 23 juillet 2008, de modernisation des institutions de la Ve République (Journal Officiel núm. 171, de 24 de julio, págs. 11890 y ss.). 
dica, esta figura parece inscribirse en la tradición iniciada, a principios del siglo XIX, por el Ombudsman sueco como órgano encargado de la supervisión de las actividades gubernamentales y administrativas en defensa de los derechos de los ciudadanos. Desde mediados del siglo XX, este tipo de órganos ha experimentado «una auténtica eclosión mundial, que ha llevado a su implantación en multitud de países", llegando a justificar la referencia a "una cierta ombudsmania ${ }^{2}$, que habría encontrado cierto eco en la propia Francia con la instauración, ya en 1973, del Médiateur de la République.

Así las cosas, cualquier observador ajeno a la vida política e institucional francesa podría creer que, en principio, el establecimiento de esta figura en Francia no habría de ser excesivamente dificultoso. Una impresión confirmada, además, por el tenor de los debates en torno a la reforma constitucional, cuya aprobación in extremis, por un único voto de diferencia, no encontró en este punto uno de sus escollos más relevantes. Y, sin embargo, cumplidos ya dos años desde la aprobación de la Ley constitucional de julio de 2008, el Défenseur des Droits no sólo sigue sin establecerse, sino que se enfrenta a múltiples obstáculos que hacen difícil, incluso, vaticinar cuándo y en qué condiciones será posible que esta figura comience a desarrollar sus funciones. En las siguientes páginas, trataremos de exponer, siquiera sea brevemente, cuál es la situación actual, así como los factores que pueden explicarla y las dificultades que complican cualquier previsión sobre el porvenir de esta figura.

\section{SU DIFÍCIL ARTICULACIÓN}

\section{CONFIguración CONSTITUCIONAL Y REMISIÓN A LA LEY}

El punto de partida inexcusable de cualquier análisis en esta materia viene dado, naturalmente, por su regulación constitucional, contenida en un nuevo Título (el XI-bis), formado por un único artículo (71-1), según el cual:

«El Defensor de los Derechos vela por el respeto de los derechos y las libertades por parte de las administraciones del Estado, las colectividades territoriales, los establecimientos públicos, así como de cualquier organismo que desarrolle un servicio público o respecto del cual la ley orgánica le atribuya competencias.

De acuerdo con las condiciones previstas en la ley orgánica, cualquier persona que se considere perjudicada por el funcionamiento de un servicio público o de un organismo referido en el primer párrafo estará legitimada para acudir al Defensor de los Derechos. Éste podrá actuar de oficio.

2 Cfr. J.M. SÁNCHEZ SAUDINÓS, «La insoportable levedad del ser: el Defensor de los Derechos establecido en la Constitución francesa", en Cuadernos de Derecho Público, núms. 34-35 (mayo-diciembre de 2008, monográfico dedicado a La reforma de la Constitución francesa), pág. 149. 
La ley orgánica definirá las atribuciones y las modalidades de actuación del Defensor de los Derechos. Determinará las condiciones en que pueda ser asistido por un órgano colegiado para el ejercicio de algunas de sus atribuciones.

El Defensor de los Derechos será nombrado por el Presidente de la República para un mandato de seis años no renovable, según el procedimiento previsto en el último párrafo del artículo 13. Sus funciones serán incompatibles con las de miembro del Gobierno y con las de parlamentario. La ley orgánica establecerá las demás incompatibilidades.

El Defensor de los Derechos dará cuenta de su actividad al Presidente de la República y al Parlamento".

De este modo, el texto constitucional señala cuál es la misión de este órgano, así como el núcleo de su régimen jurídico: nombramiento, mandato, legitimación para acudir al mismo, posibilidad de actuación de oficio, incompatibilidades, dación de cuentas... Todo ello con la concisión y generalidad propias de la Norma Fundamental, cuyo contenido básico ha de verse desarrollado por la ley orgánica prevista en aquélla.

Esta técnica conlleva, indiscutiblemente, la aparición de "incertidumbres" y dudas acerca de la configuración final de la institución. Pero ello resulta, a nuestro juicio, no sólo lógico, sino hasta cierto punto inevitable. En este sentido, basta comparar el mencionado precepto con el 54 de nuestra Constitución ${ }^{3}$ para advertir que, efectivamente, las regulaciones constitucionales suelen ser, por utilizar un término empleado por Sánchez Saudinós, "vaporosas", de modo que resulta difícil avanzar los perfiles definitivos de la institución antes de conocer el detalle de su desarrollo legislativo. Todo ello pese a las críticas que, en la doctrina francesa, han subrayado la "imprecisión total", la "vaguedad" o el "laconismo...extremo" de esta regulación, criticando "profundamente» la técnica del reenvío a la ley orgánica y llegando, incluso, hasta hablar del Defensor de los Derechos como un "objeto volante no identificado (OVNI) que aparece en el cielo constitucional ${ }^{4}$.

En todo caso, y al margen de la mayor o menor precisión de la regulación constitucional, esta figura no aparece de la nada, sino que se inscribe en un marco institucional e intelectual definido, principalmente, por dos antecedentes: el uno, ya apuntado con anterioridad, una institución preexistente, y a la que el Défenseur está llamado a suceder: el Médiateur de la République; el otro, una institución desarrollada en el plano teórico por la "Comisión de expertos" constituida por un Decreto del 18 de julio de 2007 y presidida por Edouard Balladur. Ambas referencias resultan, pues, relevantes para una me-

3 El cual, recuérdese, se limita a disponer que "Una Ley orgánica regulará la institución del Defensor del Pueblo, como alto comisionado de las Cortes Generales, designado por éstas para la defensa de los derechos comprendidos en este Título, a cuyo efecto podrá supervisar la actividad de la Administración, dando cuenta a las Cortes Generales".

4 Cfr. J. M. SÁNCHEZ SAUDINÓS, op. cit., págs. 148 y 160 (donde cita a C. TEITGENCOLLY, que ha acuñado la última imagen citada). 
jor comprensión del debate suscitado en torno al Défenseur, por lo que a ellas dedicaremos, siquiera muy brevemente, las siguientes páginas.

\section{ANTECEDENTES}

A) El Médiateur de la République

Como ya ha quedado apuntado, la mencionada "ombudsmanía" o tendencia al establecimiento de "instituciones nacionales de derechos humanos" (por utilizar la terminología de la Organización de las Naciones Unidas) encontró eco también en Francia ya desde los primeros años de la segunda postguerra mundial, como muestra la Commission Nationale Consultative des Droits de l'Homme (CNCDH, creada en 1947), y alcanzó especial concreción en la década de los años setenta del siglo XX, cuando - tras algún intento fallido- se establece el Médiateur de la République que, pese a no responder a los caracteres típicos del Ombudsman y a su mínima relevancia constitucional $^{5}$, sí constituye el "antecedente claro del Defensor de los Derechos" que ahora nos ocupa ${ }^{6}$.

De forma muy sintética cabe señalar que este Médiateur, elegido por Decreto del Consejo de Ministros para un mandato no renovable de seis años, aparece como una autoridad independiente encargada de recibir "las reclamaciones relativas al funcionamiento de las administraciones del Estado, de las colectividades territoriales, de los establecimientos públicos y de cualquier otro organismo que desarrolle una misión de servicio público, en su relación con los administrados" (artículo 1 de la Ley 73-6, de 3 de enero de 1976, reformado en 1989). Las reclamaciones pueden ser formuladas por "cualquier persona física o moral que, con ocasión de un asunto que le afecte, considere que un organismo comprendido en el artículo primero no ha funcionado conforme a la misión de servicio público que debe desarrollar" (artículo 6, modificado en el año 2000 para incluir a las personas morales). No obstante, este mismo artículo contiene una característica del Médiateur esencialmente diferenciadora del Ombudsman típico, y también del Défenseur des Droits previsto en la reforma constitucional de 2008: en efecto, tales reclamaciones deben dirigirse a un parlamentario — diputado o senador - que, a modo de

5 Para confirmar esta apreciación, baste decir que el término Médiateur no aparece siquiera en el índice onomástico (ni, a primera vista, en el texto) de muchos de los manuales más prestigiosos de Derecho Constitucional francés: vide, por ejemplo, D. GEORGES LAVROFF (Le droit constitutionnel de la Ve République, Paris, Dalloz, 1995); J. GICQUEL (Droit constitutionnel et institutions politiques, Paris, Montchrestien, 1993 para la 12. ${ }^{a}$ ed.); o L. FAVOREU et al., (Droit constitutionnel, Paris, Dalloz, 1999 para la 2. ${ }^{\text {a }}$ ed.).

6 Véase el reiterado estudio de J. M. SÁNCHEZ SAUDINÓS, a cuyas páginas 149 a 155 nos remitimos en cuanto a los urasgos característicos del Ombudsman y de las instituciones nacionales de derechos humanos", así como sobre la configuración del Médiateur y su adecuación a dichos rasgos. 
filtro, las remitirá al Médiateur "si considera que entra en su ámbito de competencias y merece su intervención".

En cuanto a sus medios de actuación, el Médiateur puede solicitar de las autoridades administrativas (que están obligadas a colaborar con él en el ejercicio de sus funciones) la documentación necesaria para dicho ejercicio, y está capacitado para hacer recomendaciones (incluyendo aquellas que permitan resolver en equidad la situación del reclamante), plantear propuestas y sugerencias (incluyendo las de modificar disposiciones legislativas o reglamentarias), iniciar acciones disciplinarias o sancionadoras contra los agentes públicos que incumplan sus obligaciones, etc. Por otra parte, habrá de ser informado acerca de los resultados de su intervención, podrá dar publicidad a la misma, y habrá de presentar ante el Presidente de la República y el Parlamento un informe anual de su actividad (artículos 9 a 14 de su Ley reguladora).

Esta somera descripción pone de manifiesto los rasgos que hacen de esta figura un claro antecedente del Défenseur, tal y como aparece constitucionalmente perfilado. Sin embargo, el nuevo precepto constitucional también encuentra un precedente esencial en las propuestas que, en su día, y como ya se expuso en crónicas anteriores, formuló el "Comité de expertos sobre la modernización y el reequilibrio de las instituciones de la V República", más conocido como Comité Balladur en virtud del nombre de la personalidad que lo presidió ${ }^{7}$. A sus conclusiones en esta materia se dedicará el siguiente epígrafe.

\section{B) El «Informe Balladur»}

Efectivamente, el "Informe Balladur" dedica al estudio de los "Nuevos derechos de los ciudadanos" su capítulo III y último. Dentro del mismo, el penúltimo de sus epígrafes postula, entre otras nuevas garantías, «instituir un Defensor de los derechos fundamentales ${ }^{8}$. Se trata, como se ha resaltado con acierto, de una iniciativa del propio Comité, pues este punto no se incluía entre aquellos que el Presidente de la República sometió a debate en el momento inicial del proceso?.

El planteamiento del Comité es, en este punto, claro: arranca de la constatación de que "la protección de los derechos fundamentales no concierne exclusivamente... a los litigios sometidos a los órganos jurisdiccionales. [Por el contrario, 1]as diferencias que enfrentan a los ciudadanos con las administraciones, así como con organismos públicos y privados de toda índole, son múltiples, ya se deban a lentitud de los servicios administrativos, a la ausencia de respuestas para las cuestiones planteadas, a los errores producidos en la tra-

7 Sobre este punto, véanse las crónicas aparecidas en los números 20 y 22 de esta misma Revista (años 2007 y 2008, páginas 562 y 458, respectivamente)

8 Une Ve République plus democratique, páginas 92-93.

9 Vide J.M. SANCHEZ SAUDINOS, ob. cit., pág. 155. 
mitación de expedientes, a las negligencias de algunos agentes públicos, a la negativa a aplicar las leyes o incluso a conflictos de competencia entre servicios. Todos estos no constituyen sino algunos ejemplos de circunstancias susceptibles de amenazar no sólo los derechos legítimos de los ciudadanos, sino también y sobre todo algunos de sus derechos fundamentales".

Para atisbar las posibles soluciones a esta situación, el Comité llamó a comparecer al Médiateur de la République. Para el Comité, "el cumplimiento de esta misión resulta más difícil por cuanto el Médiateur... no ha visto su existencia consagrada por la Constitución, y sólo puede accederse al mismo de manera indirecta, mediante los parlamentarios". Pero, además y "sobre todo", a su lado "han aparecido en los últimos años autoridades con atribuciones similares [voisines],... cuyos ámbitos de competencia respectivos parecen comer terreno [empiéter] en todo o parte al del Médiateur. La consecuencia de esta situación es «una dilución de responsabilidades perjudicial por sí misma para los derechos de los ciudadanos. Estos últimos, ante errores administrativos que afectan a sus derechos fundamentales, no saben incluso a qué organismo dirigirse para hacer valer sus derechos".

Como conclusión, y explícitamente "inspirado por el éxito experimentado en España por el Defensor del Pueblo mencionado en el artículo 55 [sic] de la Constitución", el Comité formula una propuesta ${ }^{10}$ que, una vez más de manera abierta, reconoce al Médiateur como antecedente inmediato. Se trata, en definitiva, de modificar la denominación del Mediador de la República y consagrar expresamente en un título de la Constitución la existencia de un "Defensor de los derechos fundamentales", cuyas características recuerdan mucho, efectivamente, al modelo español, si bien conservan también algunos elementos del Médiateur.

De esta forma, el Informe proponía "instituir un Defensor de los derechos fundamentales, reuniendo en particular todas o parte de las atribuciones del Médiateur de la République, del Défenseur des enfants, del Contrôleur général des lieux de privation de liberté, de la Halde [Haute autorité de lutte contre les discriminations et pour l'égalité] y de la CNIL [Commission nationale de l'informatique et des libertés]. Dicho organismo, de acuerdo con el modelo español, habría de ser elegido por una mayoría cualificada (tres quintos) de la Asamblea Nacional, entre los candidatos propuestos por una Comisión ad hoc constituida en la misma; estaría "habilitado para interponer recursos ante el Consejo Constitucional", y debería ser accesible directamente para "toda persona "11

10 Proposition número 76 (sobre un total de 77).

11 La influencia del modelo de Defensor del Pueblo español (quien también compareció ante el Senado francés en mayo de 2008, durante el proceso de elaboración de la ley constitucional "para informar sobre las características y el funcionamiento de la institución en España": vide J.M. Sánchez Saudinós, op. cit., pág. 157) puede apreciarse también en otros aspectos que se recogen en el Informe, pero no llegan a incluirse en el texto del artículo propuesto. Es el caso, en particular, de la posibilidad de que la ley orgánica prevea "que Defensores Adjuntos le ayuden a ejercer su misión". 
Todo ello se concretaba en la propuesta de introducir en el texto constitucional un nuevo Título (XIII bis), compuesto por un artículo único (el 78) con el siguiente texto:

«El Defensor de los Derechos fundamentales vela por el respeto de los mismos de oficio o a instancia de cualquier persona.

A instancia de los interesados, asegurará igualmente el buen funcionamiento de los organismos que desarrollen un servicio público.

[El Defensor] formulará recomendaciones y requerimientos [mises en demeure] en los casos y según los procedimientos determinados por una ley orgánica. Ésta podrá confiarle [asimismo] potestades de decisión, de mediación o de transacción en las condiciones que establezca.

El Defensor de los derechos fundamentales puede recurrir al Consejo Constitucional en las condiciones previstas por el artículo $61.2^{12}$. No podrá intervenir en procesos jurisdiccionales, ni cuestionar los fundamentos de una resolución judicial.

[El Defensor] dará cuenta de su actividad al Presidente de la República y al Parlamento.

Será nombrado por la Asamblea Nacional, por una mayoría de tres quintos, para un mandato de seis años no renovable».

En definitiva, el Informe del Comité concluía este punto afirmando su "convicción de que habida cuenta las dificultades que en ocasiones nuestros conciudadanos deben afrontar, la creación de tal autoridad, única elegida por la Asamblea Nacional y cuya misión sería incompatible con el ejercicio de un mandato parlamentario, no solamente respondería a una necesidad real, sino que además mejoraría el funcionamiento global de nuestras instituciones" ${ }^{13}$.

\section{C) Del "Comité Balladur» a la Constitución}

En todo caso, como ya se examinó en la crónica anterior, el proceso de revisión constitucional culminó con la aprobación, por un único voto, de la ley constitucional de julio de 1998, que modificaba más de la mitad de los preceptos de la Norma Fundamental vigente en ese momento.

Pues bien: en el punto que ahora nos interesa, la ya señalada recepción constitucional de esta figura, como sucesor del Médiateur, no puede ocultar el abandono de gran parte de las características que la adornaban en el Informe

12 Artículo que regula el recurso previo de inconstitucionalidad frente a las leyes que pueden plantear el Presidente de la República, el Primer Ministro, los Presidentes de las Cámaras parlamentarias, sesenta diputados o sesenta senadores.

13 Página 93. Las cursivas, añadidas por el autor de estas páginas, remarcan la excepcionalidad del procedimiento de elección propuesto que, como ya se ha anticipado, explica en gran parte su abandono, para ajustarse a esquemas más habituales en el ordenamiento constitucional francés. 
del Comité Balladur. En particular, como también se ha apuntado, aspectos especialmente próximos al modelo español, tales como el procedimiento de elección o la legitimación para interponer recurso de inconstitucionalidad contra las leyes, se han perdido en el debate de la reforma. Un debate que, además, desembocó en el cambio no sólo de su denominación (de "Defensor de los derechos fundamentales" a "Defensor de los derechos") sino también —e, incluso, fundamentalmente- de su naturaleza ${ }^{14}$.

Porque, en efecto, el Comité de expertos concibió esta figura —ya desde su denominación, y su ubicación en el Informe- fundamentalmente como una técnica de garantía de los derechos fundamentales, asignándole la doble función de "velar por el respeto de los mismos" asegurando "igualmente el buen funcionamiento de los organismos" que desarrollen funciones públicas. Pero lo cierto es que el texto definitivo refunde ambas misiones en una sola, al asignarle eel respeto de los derechos y las libertades por parte de las administraciones del Estado". Una modificación que, por ejemplo, justifica la mencionada desaparición de la legitimación para interponer recursos de inconstitucionalidad frente a leyes que, evidentemente, no constituyen actuaciones administrativas ${ }^{15}$.

En todo caso, la recepción constitucional de esta figura supone un dato novedoso. Ciertamente, sus funciones quedan esencialmente indefinidas, eliminando las concreciones que incluía el Informe del Comité y supeditándose a su determinación por ley orgánica. Asimismo, es obvio que - como subraya, nuevamente con acierto, Sánchez Saudinós- el rango constitucional del Defensor le otorga "un status y una legitimidad únicas", que deberían favorecer la asunción de «un papel coordinador respecto al universo de autoridades administrativas independientes" que el Comité Balladur pretendía reemplazar.

Sin embargo, los datos ponen de manifiesto, con toda claridad, que las cosas no parecen tan sencillas. De hecho, como apuntábamos al inicio de estas páginas, cumplidos ya dos años desde la aprobación del texto constitucional éste sigue sin estar vigente en este punto, ya que su entrada en vigor habrá de producirse en las condiciones fijadas por las leyes necesarias para su aplicación ${ }^{16}$. Y, en la fecha en que se redactan estas páginas, tales condiciones están muy lejos de poder precisarse. En particular porque, como analizaremos a continuación, la instauración de esta figura ha provocado una viva controversia relativa, en particular, al futuro de las diversas autoridades que, como recordaba el Informe Balladur, tienen actualmente atribuidas funciones similares.

14 Sobre este punto, véase, una vez más, el citado trabajo de J.M. SÁNCHEZ SAUDINÓS, ob. cit., págs. 157 a 159.

15 Por más que algunos autores galos sugieran la posibilidad de un acceso "indirecto" al Consejo Constitucional, que sería factible si la ley orgánica atribuyese al Defensor la facultad de "dirigirse al Consejo de Estado" al efecto de que éste, conforme al procedimiento de control incidental de constitucionalidad introducido en 2008 en el nuevo artículo 61-1 de la Constitución, pueda plantear ante el Constitucional, con ocasión de un proceso en curso, dudas sobre la inconstitucionalidad de una disposición legislativa (loc. cit., págs. 164-165).

16 Artículo 46-I de la loi constitutionnelle de 23 de julio de 2008. 


\section{LA DiFíCIL CONFIGURACIÓN LEGAL}

En efecto, desde la aprobación de la reforma constitucional pasó más de un año hasta que, el día 9 de septiembre de 2009, el Consejo de Ministros presentó ante el Senado ${ }^{17}$ los proyectos legislativos llamados a desarrollar la nueva figura.

\section{A) Los proyectos}

De acuerdo con la referencia del Consejo de $\operatorname{Ministros}^{18}$, la recepción constitucional del Defensor de los derechos persigue "reforzar sustancialmente las posibilidades de recurso no jurisdiccional a disposición de los ciudadanos para asegurar la defensa de sus derechos y libertades". El cumplimiento de tales objetivos requiere, de acuerdo con el sistema de fuentes del derecho vigente en Francia, una doble norma: de una parte, y conforme a la remisión establecida en el ya conocido artículo 71-1 de la Constitución, una ley orgánica que precise «el estatuto, las funciones y las atribuciones del Defensor de los derechos"; de otra, conforme al ámbito reservado a la ley por el artículo 34 C., una ley ordinaria que "complete el texto orgánico previendo, esencialmente, las sanciones penales" asociadas al "desconocimiento de las disposiciones relativas a las facultades de investigación del Defensor de los derechos".

De esta forma, los textos remitidos por el Gobierno al Senado presentaban las siguientes características esenciales:

a) El proyecto de ley orgánica (relativo al Defensor de los derechos)

a.1. De acuerdo con el mandato constitucional, el nombramiento se atribuye al Consejo de Ministros, mediante el procedimiento previsto, tras la reforma de 2008, en el último apartado del artículo 13 de la Constitución ${ }^{19}$; y su cese sólo puede producirse en caso de renuncia o de imposibilidad de ejercer

17 Recuérdese que, conforme al artículo 39 de la Constitución, los proyectos de ley pueden presentarse, como regla, ante la Mesa de cualquiera de las Cámaras, estableciéndose únicamente, como excepción, ciertos casos que han de someterse en primer lugar ya a la Asamblea Nacional, ya al Senado.

18 Disponible en http://www.gouvernement.fr/print/gowvernement/defenseur-des-droits.

19 Según el cual, "el poder de nombramiento del Presidente de la República" de ciertos cargos o funciones, «en razón de su importancia para la garantía de los derechos y libertades o para la vida económica y social de la Nación" sólo podrá ejercerse "tras informe [avis] público de la Comisión permanente competente de cada Cámara”. Es más: «El Presidente de la República no podrá proceder al nombramiento cuando la suma de votos negativos en cada Comisión represente como mínimo tres quintos de los votos emitidos". En definitiva, la propuesta del Comité Balladur (nombramiento por mayoría de tres quintos de la Asamblea) se reconduce a este nuevo mecanismo, que atribuye a las Comisiones parlamentarias competentes un auténtico "poder de veto", por más que éste sea difícil de imaginar en la práctica. 
el cargo, en las condiciones que defina un decreto dictado tras audiencia del Consejo de Estado (artículo 1). Su estatuto se contiene esencialmente en los artículos 2 (el Defensor no recibirá instrucciones de ninguna otra autoridad en el ejercicio de sus funciones, gozando además de las prerrogativas de inviolabilidad e inmunidad) y 3 (que prevé un riguroso régimen de incompatibilidades, ampliando el mínimo constitucionalmente establecido para extenderse a "todo mandato electivo" o "cualquier otra función o empleo público", así como a "toda actividad profesional") ${ }^{20}$.

a.2. El título II de la ley regula las "reclamaciones". Éstas pueden formularse, según el modelo tradicional del Médiateur, de manera indirecta ante diputados o senadores, que pueden transmitirla al Defensor (art. 7); sin embargo, en la nueva lógica de la institución, el mecanismo normal es el de su presentación por "cualquier persona física o moral que se considere lesionada en sus derechos" por el funcionamiento de cualquier administración u organismo que desarrolle un servicio público; o, incluso, en algunos casos (protección de menores o infracciones a las reglas de la deontología en materia de seguridad), por la actividad de sujetos privados (artículo 4); tales reclamaciones, además, serán gratuitas (artículo 6).

a.3. En cuanto a su compleja relación con otras autoridades independientes, este proyecto dispone que:

En primer lugar, "cuando el Defensor... transmite una reclamación a otra autoridad independiente investida de una misión de protección de los derechos y libertades, puede acompañarla de sus observaciones y demandar que se le informe" de sus consecuencias (artículo 9, párrafo primero).

Además, el Defensor "estará asociado, a petición propia, a los trabajos de la Haute autoricé de lutte contre les discriminations et pour l'égalité [HALDE] et de la Commission nationale de l'information et des libertés [CNIL]" (artículo 9, párrafo segundo).

De otra parte, según el artículo 33, "el Defensor de los derechos sucede al Médiateur de la République, al Défenseur des enfants y a la Commission nationale de déontologie de la sécurité [CNDS]". Pero esta sucesión se traduce en un complejo esquema orgánico, plasmado en la creación de unos "colegios" según se detalla en los artículos 11 y 12. De este modo, cuando el Defensor intervenga en materia de deontología de la seguridad o con el objeto de proteger los derechos de un niño, "consultará a un colegio compuesto por tres personalidades designadas respectivamente" por los Presidentes de la República, de la Asamblea Nacional y del Senado, "en razón de su competencia" en los ámbitos concernidos.

a.4. En lo que atañe a su estructura y organización, además de estos "COlegios" consultivos el proyecto abandona la idea de los Adjuntos, previendo - en una línea mucho más continuista con el Médiateur actual— la existencia de "delegados, sometidos a su autoridad, que en su ámbito geográfico pueden instruir reclamaciones y participar" en sus actividades, y a los que el De-

20 Además, el artículo 31 desarrolla las inelegibilidades del Defensor de los derechos. 
fensor puede delegar algunas de sus facultades. Además, dispondrá de "servicios sometidos a su autoridad, comprendiendo funcionarios civiles y militares, magistrados" y otros agentes, que también pueden ser beneficiarios de la mencionada delegación (art. 28). Todos ellos, lógicamente, están sujetos al secreto profesional respecto de los asuntos que conozcan en el ejercicio de sus funciones.

a.5. En otro orden de cosas, el proyecto regula los medios de información y actuación del Defensor: entre los primeros, a grandes rasgos se establece que las personas públicas y privadas cuyas actuaciones se cuestionan deben facilitar el ejercicio de su misión, respondiendo a las cuestiones que éste les plantee, enviando cuanta información se les requiera; además, se reconoce también la facultad de proceder a verificaciones sobre el terreno en las dependencias administrativas o privadas relevantes.

a.6. Por último, y en lo relativo a sus facultades, cabe resaltar que el Defensor puede apreciar libremente (souverainement) la conveniencia de intervenir en respuesta a una reclamación, sin que necesite motivar su rechazo (art. 20). Por lo demás, puede hacer recomendaciones, sugerir medidas o reformas legislativas o reglamentarias, proponer transacciones, promover procedimientos disciplinarios, informar al Procurador de la República cuando estime que los hechos objeto de la reclamación son constitutivos de delito... Incluso, pese a que no pueda cuestionar una decisión judicial, sí se prevé la posibilidad de que, de oficio o por invitación de los órganos jurisdiccionales, presente "observaciones escritas u orales" (art. 26). Finalmente, el artículo 27 prevé que el Defensor "presentará cada año un informe al Presidente de la República, al Presidente de la Asamblea Nacional y al Presidente del Senado, dando cuenta de su actividad. Dicho informe será objeto de una comunicación del Defensor... ante cada una de las Cámaras, y será publicado".

b) El proyecto de ley (relativo al Defensor de los derechos)

Mucho más simple, se limita a establecer las sanciones derivadas de la infracción de las obligaciones establecidas por la ley orgánica, y a modificar las leyes que se ven afectadas por la instauración de la nueva figura. En este último sentido cabe destacar que afecta, en particular:

A aquellas leyes en las que se regulan la CNIL y la HALDE, incorporando a su composición la ya mencionada presencia del Defensor de los derechos o su representante "Con vOz, pero sin voto" (artículos 1 y 2 ).

A aquellas otras en que se menciona al Médiateur, solo o acompañado por el Defensor de los niños o el Presidente de la Comisión nacional de la deontología de la seguridad [CNDS].

Y, finalmente, se derogan las leyes que crean o instituyen estas tres últimas figuras (artículo 14). 
B) Las dificultades

Así las cosas, no parece difícil adivinar que el texto más relevante, y también más discutido, es el de la ley orgánica. Y que, más en particular, las principales cuestiones suscitadas son las que no resolvió el texto finalmente aprobado en el marco de la revisión constitucional. Porque, como enseguida se encargó de resaltar la doctrina, el texto constitucional dejaba "en una nebulosa" el ámbito competencial del Defensor y, en íntima relación con ello, su posición "en el organigrama de las autoridades administrativas independientes que actúan en materia de protección de las libertades ${ }^{21}{ }^{21}$. Aspecto este último que, como ya resaltara J. M. Sánchez Saudinós en su examen de esta institución, ha sido muy polémico tanto doctrinal como políticamente ${ }^{22}$.

En efecto, en la doctrina el citado autor distingue la existencia de autores que, en línea con los argumentos del Comité Balladur, consideran que la nueva institución contribuirá a la "racionalización de la estructura" de estas autoridades, "que el Defensor está llamado a federar o coordinar" porque, sólo en tal caso, "la figura tendrá un alcance efectivo" (B. Mathieu). Otros, por el contrario, estiman que la integración de todas estas autoridades "ni se vislumbra ni es deseable, además de ser difícil de asumir políticamente", por más que "la coexistencia pura y simple" del Defensor con las mismas "tampoco [sea] deseable (N. Marcon). Es más: algún autor (D. Rousseau) llega a sugerir que la nueva figura viene a incrementar la complejidad de la arquitectura institucional francesa...

La dificultad (por no decir imposibilidad) de integrar todas estas posturas justifica la viva polémica planteada, desde el primer momento, en este punto. En efecto, ya desde la formulación de las propuestas del Comité Balladur, y por tanto mucho antes de la presentación de los proyectos de ley, la recepción de esta figura "no fue muy acogedora por parte de los organismos, entidades u otras instituciones dedicadas a la protección de los derechos, ni tampoco suscitó especial entusiasmo entre las instituciones o autoridades independientes que proponía fusionar ${ }^{23}$. Pero, como es lógico, las reacciones - casi siempre negativas - se reavivaron y fortalecieron a partir de la presentación de estos proyectos que, obviamente, venían a despejar las vaguedades anteriormente subrayadas, concretando los organismos afectados y el grado de afectación.

Por eso, no puede extrañar el especial protagonismo adquirido en esta "resistencia" por la titular de uno de los organismos llamados a desaparecer: la "Defensora de los niños" (Défenseure des enfants), Dominique Versini. Esta antigua Secretaria de Estado del Gobierno conservador de J.-P. Raffarin (20022004) se pronunció, desde el primer momento, radicalmente en contra de una

21 Vide, una vez más, J. M. SÁNCHEZ SAUDINÓs (op. cit., págs. 159-161), y la doctrina francesa allí citada (N. MARCON, B. FRANÇOIS, etc.)

22 Ibidem, págs. 165-166.

23 Ibidem, páginas 157 y 165. 
decisión que, a su juicio, no ha sido consultada, y que además ofrece múltiples inconvenientes sin apenas ninguna ventaja. En un primer comunicado de prensa, emitido el día 15 de septiembre de $2009^{24}$, la Defensora exponía haber descubierto, "con estupor", los dos proyectos que suprimen dicha Institución, y se preguntaba "por qué el Gobierno ha decidido limitar el ámbito de actuación" del nuevo órgano a las competencias de las tres autoridades afectadas, excluyendo otras tan fundamentales como las relativas a las discriminaciones, el control de las instituciones penitenciarias y centros de privación de libertad, o la protección de la vida privada frente a la multiplicación de los ficheros informáticos, que seguirían gestionados por la HALDE, el Contrôleur général des lieux privatifs de liberté (CGPL) y la CNIL. En definitiva, la Defensora expresaba "su total desacuerdo con el hecho de que se haya decidido, arbitrariamente y sin ninguna concertación, disolver ciertas autoridades independientes e instrumentar una simple articulación con otras", reclamando al Gobierno que explicase la lógica por la cual se decide suprimir, a mitad de su mandato, una institución cuyo trabajo de los derechos del niño es unánimemente reconocido, tanto en Francia como en el extranjero.

El segundo de los comunicados (del 21 de septiembre) se abría señalando que «en el momento en que el Gobierno francés decide suprimir el Defensor de los niños, D. Versini [su titular] asume la Presidencia de la red europea de Defensores de los niños, reunida en Paris", preguntándose: "el año 2009, ¿pasará a la historia como aquel elegido por el Gobierno francés para suprimir la institución a la que la ley ha encargado, desde hace nueve años, de velar por el respeto de los derechos del niño?».

El mismo tono altamente crítico se encuentra en todos los documentos citados, donde se exponen otros muchos argumentos. Entre ellos cabe subrayar, de forma muy sintética, los siguientes:

a) La menor visibilidad de la nueva institución para unos menores que ya han identificado claramente al Defensor de los niños como encargado de defender sus derechos.

b) La desaparición de la institución implica la finalización de las funciones de su titular cuyo mandato, según la ley, no puede finalizar sino en ciertos casos legalmente previstos.

c) El retroceso respecto de ciertos aspectos concretos, pero fundamentales, entre los cuales se destacan:

- La desaparición de la función de "promoción de los derechos del niño".

24 En los párrafos siguientes, se utilizan citas y argumentos extraídos de diversos documentos: comunicados de prensa de los días 15 y 21 de septiembre de 2009 (esto es, pocos días después de la aprobación gubernamental de los proyectos de ley); un dictamen sobre los mismos, y un editorial de 12 de febrero de 2010; todos ellos, accesibles en la página web de la institución (www.defenseurdesenfants.fr). 
- La dilución de la misión de propuesta de modificaciones legislativas y reglamentarias dirigidas a transponer los compromisos internacionales en el derecho interno.

- Reducción del ámbito de defensa de los derechos del niño al derecho interno: el proyecto no alude a las normas internacionales, de modo que los derechos así protegidos serían únicamente los que encuentren reflejo en el derecho interno.

d) Por otra parte, se cuestiona también la utilidad del colegio consultivo para la protección de la infancia, considerando que el procedimiento necesario para ponerlo en práctica resulta dudosamente eficaz a la vista de la urgencia de las situaciones a las que habitualmente se enfrenta el Defensor de los niños, y que han llevado a instituir en su seno un Comité de evaluación interna que se reúne tres veces por semana, a fin de responder inmediatamente a cualquier urgencia.

e) Además, "la Defensora de los niños considera" que los medios de actuación previstos para la nueva figura no aportan en la gran mayoría de sus intervenciones capacidades suplementarias a las que ya se ejercen.

f) Se critica igualmente el que el Defensor de los derechos no haya de justificar las razones por las que no admite a trámite una reclamación, en contra de los usos instaurados en el Defensor de los niños...

En definitiva, «la desaparición del Defensor de los niños por absorción en el Defensor de los derechos no presenta avances notables y comporta incluso retrocesos para la defensa y promoción de los derechos de los menores". Por todo lo cual, se solicita ("demande") modificar el apartado segundo del artículo 9 del proyecto de ley orgánica, estableciendo entre los Defensores de los derechos y de los niños una articulación similar a la propuesta para la HALDE y la CNIL (asociación del Defensor de los derechos a sus trabajos, a petición propia). Ello, obviamente, permitiría al Defensor de los niños mantener sus funciones, apoyándose en caso de necesidad en la nueva figura constitucionalmente recogida.

El problema para los promotores del Defensor de los derechos es que estas objeciones han recibido múltiples apoyos de organizaciones y sectores sociales relevantes ${ }^{25}$. Y que otras similares se han hecho, con más o menos virulencia, desde las restantes instituciones afectadas. Así, puede mencionarse igualmente el Informe sobre el Defensor de los derechos emitido por la Com-

25 Así, una campaña de adhesiones "a favor de un Defensor de los niños independiente" ha alcanzado no sólo más de 50.000 apoyos explícitos sino, sobre todo, el de una lista auténticamente impresionante de ONGs e instituciones, entre las cuales cabe citar a UNICEF-Francia, SOSRacismo, la Liga de Derechos del Hombre, la Red Europea de Defensores de los Niños, la Oficina Internacional Católica de la Infancia, el Presidente de la Cruz Roja francesa, Sindicatos y asociaciones profesionales, partidos políticos... Todo ello, con un alcance que excedía claramente el de la mayoría politica, como muestra por ejemplo el voto unánime de los grupos municipales en la villa de París. 
mission nationale consultative des droits de l'homme (CNCDH), pionero entre los órganos nacionales franceses para la defensa de los derechos ${ }^{26}$. En el mismo, la Comisión subraya que el Gobierno ha favorecido los planteamientos del Médiateur de la République, en detrimento de otros alternativos, y cuestiona la amputación de los mandatos de los titulares de las instituciones afectadas, que afecta a la independencia de estas autoridades, como una de las garantías esenciales del cumplimiento de su misión. Por eso, aunque "saluda la creación" de la nueva autoridad, considera que su institución "sustituyendo a autoridades que han demostrado su eficacia efectuando las mismas tareas, constituiría una regresión". Así pues, a juicio de la CNCDH deberían "mantenerse las autoridades existentes, ya resulten directa o indirectamente afectadas por el proyecto... actual, a excepción del Mediador de la República”. Asumiendo "la coordinación de la misión de defensa de los derechos... el Defensor... deberá contribuir a la cooperación y a la coordinación de autoridades no concurrentes, sino complementarias..... En síntesis, "beneficiándose [de su peso constitucional] y de una gran visibilidad, el Defensor podrá transmitir las reclamaciones... a la autoridad más competente para tratarlas, de manera sistemática, coordinada y concertada ${ }^{27}$.

El resultado global de todo este proceso de debate social ha sido el de alterar profundamente los términos de la discusión: en efecto, en el momento actual la cuestión no es ya tanto la de los perfiles de una figura nueva y, por tanto, aún por descubrir; sino la del mantenimiento de otras figuras ya operativas y, por tanto, conocidas y concretas, con recursos propios que les permiten intervenir en defensa de sus propias posiciones.

Y ello, naturalmente, no podía dejar de tener incidencia en el debate político. Así lo anticipaban, por ejemplo, los anteriormente apuntados apoyos obtenidos por la campaña de mantenimiento de un "Defensor del menor" independiente. Así se desprende claramente también de las posiciones expuestas por algunos referentes de la izquierda política, como el antiguo Primer Ministro Lionel Jospin quien, tras denunciar públicamente "la inaceptable regresión" de las libertades, considera "la creación de un Defensor de los derechos [como] un simple pretexto para suprimir dos organismos frecuentemente críticos frente a los excesos de la política de seguridad" del actual gobierno $^{28}$. Y así lo han confirmado los primeros - y difíciles- pasos del iter parlamentario de los proyectos de ley que ahora nos ocupan, como pasamos a exponer inmediatamente.

$26 \mathrm{El}$ informe fue adoptado, de forma ampliamente mayoritaria, por la Asamblea plenaria del organismo el 4 de febrero de 2010.

27 Algunas otras opiniones críticas, como las de la Comisión nacional de deontología de la seguridad (CNDS), o la Alta autoridad de lucha contra la discriminación y la igualdad (HALDE) pueden encontrarse resumidas en un artículo accesible en Le Monde digital (www.lemonde.fr): "Les institutions rattachées au futur Défenseur des droits revendiquent leur spécificité" (2 de junio de 2010).

28 Tribuna publicada en Le Monde, y citada en el artículo citado supra, en la nota 26. 


\section{C) El debate político y parlamentario}

a) El tiempo y el contexto. Un primer dato a considerar es, evidentemente, el del tiempo. Porque, en efecto, no deja de ser significativo que unos proyectos presentados por el Gobierno en septiembre de 2009 no hayan iniciado su tramitación hasta el segundo trimestre de 2010 y, en el momento actual, sólo hayan superado, con las vicisitudes que describiremos muy brevemente, el primer trámite (primera lectura en el Senado), de modo que está aún pendiente su discusión y eventual modificación o aprobación por parte de la Asamblea nacional ${ }^{29}$. Todo lo cual ha obligado a adoptar ciertas medidas provisionales y, en particular, una ley para prorrogar el mandato del actual Médiateur de la République, que debería haber expirado en abril de este mismo año $2010^{30}$. De este modo, el artículo único de esta disposición establece que "por derogación del artículo 2 de la ley n. ${ }^{\circ} 73-6$, de 3 de enero de 1973, que instituye un Mediador de la República, la duración del mandato del Mediador [actual]... desde el 13 de abril de 2004 se prorrogará hasta la fecha de entrada en vigor de la ley orgánica prevista en el artículo 71-1 de la Constitución y, como máximo, hasta el 31 de marzo de 2011,31.

En todo caso, este retraso encuentra una explicación objetiva en la polémica social e institucional ya esbozada y en el consiguiente cambio de perspectiva del debate en su conjunto. Pero a este dato se suman sin duda razones subjetivas, en tanto que los argumentos críticos han encontrado amplio eco político, que exceden incluso al ámbito de la oposición política y parlamentaria. De este modo, en una materia como ésta - en principio, tan propicia para la construcción de acuerdos - se ha producido una polémica que, en primera instancia, parece haber obligado a la mayoría política a "cerrar líneas" en torno a unas posiciones gubernamentales que, en la misma medida, son cambiantes. Y que, por encima de ello, registra un choque frontal entre la mayoría (presidencial y parlamentaria, desde 2007) y las minorías de oposición, reproduciendo así la situación que, en el momento de la reforma constitucional de 2008, desembocó en su aprobación por tan solo un voto ${ }^{32}$. En definitiva, y aunque este punto no fue especialmente debatido entonces, la situación resulta ser similar, y los debates políticos y parlamentarios son un fiel reflejo de ello.

29 En el momento presente (septiembre de 2010), el texto se halla sometido a la Commission des lois de la Asamblea, que el 16 de junio último nombró como ponente (rapporteur) al diputado M. Pierre Morel-A-L'Huissier.

30 Actualmente, el Médiateur de la République es el ex Ministro (gaullista-UMP) Jean-Paul Delevoye, quien fue nombrado por el Presidente Chirac en 2004, y —según la prensa francesa- es el más serio candidato a inaugurar el cargo de Défenseur des droits, en lo que sin duda sería un elemento más de continuidad entre ambas instituciones.

31 Loi n. 2010-372 du 12 avril 2010 visant a proroger le mandat du Médiateur de la République. Como puede apreciarse, pues, se establece una fecha tope (el 31 de marzo de 2011), pero no se excluye que la nueva ley entre en vigor incluso en una fecha posterior.

32 Vid. TRC, número 22, citado, páginas 459-460 y 470-471. 
b) La tramitación parlamentaria

b.1) El primer paso en la tramitación parlamentaria — conjunta— de los dos proyectos de ley sobre el Defensor de los derechos fue la elaboración de la ponencia (rapport) encomendada, por la Comisión de leyes del Senado, a un conocido senador de la mayoría (Union pour un Mouvement Populaire, UMP), Patrice Gélard. El 19 de mayo, la citada Comisión aprobó un texto que incluía la adopción de numerosas enmiendas ( 41 al texto orgánico; 10 más, al ordinario) que responden, con toda claridad, al debate social suscitado, y afectan a aspectos centrales de la figura proyectada, asumiendo buena parte de las críticas expuestas. Entre tales cambios cabe destacar los siguientes:

b.1.1. En primer lugar, aquellos relativos al ámbito de competencia del Defensor, y por consiguiente a la articulación de sus relaciones con otras autoridades independientes para la defensa de los derechos. Se trata, sin duda, de la variación de mayor alcance, y con mayores repercusiones en la estructura de la nueva figura. Dentro de este marco, cabe destacar en particular dos aspectos:

- La atribución al Défenseur de competencias en materia de lucha contra toda discriminación, ya sea ésta directa o indirecta (artículo 4, párrafos segundo y quinto).

- Esta modificación competencial conlleva múltiples y relevantes consecuencias. En particular, implica la supresión de la Haute autorité de lutte contre les discriminations et pour l'égalité (HALDE), cuya ley reguladora es por tanto derogada (art. 14 de la ley ordinaria), y cuyas funciones son asumidas por el Défenseur des droits, con las consiguientes reformas del texto orgánico (entre otros, los artículos 10, 12 bis, 15, 22, 23 bis, 25 o 26 bis).

- Asimismo, la posibilidad de que el Defensor se asocie voluntariamente a los trabajos de otra institución queda limitada, lógicamente, a la CNIL; mientras que se introduce la previsión de establecer convenios con cualesquiera otras autoridades independientes competentes en materia de protección de derechos y libertades (art. 9, párrafos tercero y segundo, respectivamente).

b.1.2. Al mismo tiempo, y en cuanto a su organización interna, no sólo se prevé la elaboración de un reglamento interno y de un código de deontología propio (art. 29 bis), sino que la propia estructura de la institución se ve profundamente modificada.

- En particular, los "colegios consultivos" previstos en el proyecto anterior resultan prácticamente irreconocibles. Primero, porque su número se eleva a tres (uniéndose a los anteriores, en materia de deontología de la seguridad y de derechos del niño, un tercero, en materia de lucha contra las discriminaciones y promoción de la igualdad). Pero, además, porque su estructura sufre un cambio significativo, y además diferente en cada caso. 
- De este modo, los tres "colegios" consultivos, compuestos cada uno de ellos por personas de reconocida competencia y experiencia en la respectiva materia, serán presididos por el Defensor, y en cada uno de ellos se integrará, como vicepresidente, un "adjunto", nombrado por aquél tras oír a las respectivas comisiones parlamentarias, y con un campo específico, pues, de actuación. Tales adjuntos, sometidos a la autoridad del Defensor, pueden actuar por delegación del mismo, presidiendo las reuniones de sus respectivos colegios, y representarle (en su ámbito de competencia propio) ante las organizaciones internacionales correspondientes (art. $11 \mathrm{~A}$ ).

- Más allá de esos elementos comunes, la composición de cada colegio es diferente (artículos 11, 12 y 12 bis), siendo especialmente llamativa su considerable ampliación. De este modo, y junto al Defensor y al adjunto respectivamente nombrado ratione materiae, los colegios quedan organizados así:

- En materia de deontología de la seguridad, se integran otros 12 miembros (dos senadores, dos diputados, un Consejero de Estado, un Magistrado, un Consejero de cuentas y cinco personalidades nombradas por el Defensor de los derechos).

- En materia de defensa y promoción de los derechos del niño, se integran en el colegio nueve miembros adicionales, designados por los Presidentes del Senado, de la Asamblea Nacional y el Ministro de Justicia (dos en cada caso); y 3 personalidades cualificadas designadas por el Defensor.

- En el ámbito de la lucha contra las discriminaciones y la promoción de la igualdad, los miembros adicionales nombrados son también nueve, si bien cambian algunas de las autoridades que los designan: los Presidentes de las dos Cámaras, como el Primer Ministro, designan a dos; mientras que los tres restantes son designados por el Vicepresidente del Consejo de Estado, el Primer Presidente de la Corte de Casación y el Presidente del Consejo Económico, Social y Medioambiental.

- En todos los casos, el Defensor puede solicitar a los respectivos colegios una segunda deliberación sobre un asunto, y sólo puede alejarse de su informe justificando los motivos de su discrepancia.

- Por lo demás, se mantiene la estructura de delegados y agentes presente ya en el proyecto de ley gubernamental. tivas:

b.1.3. Junto a esas importantes modificaciones, se introducen otras rela-

- Al ejercicio de sus funciones: en particular, la obligación de motivar la inadmisión a trámite de cualquier reclamación (artículo 20).

- Al parámetro de su actividad, incorporándose especialmente la previsión de que puede actuar en defensa de los derechos reconocidos por tratados internacionales. 
- A sus facultades: capacidad de dictar requerimientos (art. 17 bis); de proceder a la resolución amistosa de conflictos, por vía de mediación (art. 21 bis); precisión de los términos en que puede proponer una transacción, especialmente en materia de discriminación (art. 22, apartados II a V).

- Además, se introducen nuevas funciones consultivas (preceptivas, sobre todo proyecto de ley relativo a la lucha contra la discriminación y la promoción de la igualdad; o facultativas, sobre cualquier asunto relativo a su ámbito de competencia, a instancia del Primer Ministro o de cualquiera de los Presidentes de las Cámaras). También en este ámbito, y a petición del Primer Ministro, puede contribuir a la preparación y definición de la posición francesa en las negociaciones internacionales y formar parte de la representación francesa en las organizaciones internacionales, siempre en sus ámbitos de competencia (art. 25).

- Asimismo, se otorga especial importancia a las funciones de promoción (comunicación, información, formación o promoción, en sentido estricto) en su ámbito de actuación.

Finalmente, el texto establece una entrada en vigor escalonada: en principio, su vigencia se pospone al primer día del tercer mes siguiente a su publicación, momento en que el Défenseur sucederá al Médiateur en todos sus derechos, obligaciones y actividades. Sin embargo, en las "materias específicas" asumidas por la nueva figura (deontología de la seguridad, protección de los derechos de los niños y lucha contra la discriminación) las respectivas instituciones, llamadas a desaparecer, permanecerán durante cinco meses sometiéndose a las reglas actualmente vigentes; y sólo el primer día del quinto mes siguiente a la publicación de la ley el Défenseur asumirá sus funciones, entrando plenamente en vigor la ley.

b.2) En todo caso, tales cambios no fueron suficientes para asegurar la aceptación pacífica y consensuada de los textos, como pusieron claramente de manifiesto los debates de los proyectos de ley celebrados en el Senado, los días 2 y 3 de junio.

b.2.1. En efecto, en la primera de esas sesiones, la Cámara adoptó, tras un profundo debate, una serie de enmiendas dirigidas, ni más ni menos, que a mantener la institución del Defensor de los niños, impidiendo pues la transferencia de sus competencias al Defensor de los derechos. Como quiera que dichas enmiendas fueron promovidas por senadores de los grupos conservador (UMP) y centrista (UC), el voto de estos grupos se fraccionó, permitiendo así que, en primera instancia, la Cámara decidiese contradecir frontalmente el propósito gubernamental de integrar ambas instituciones ${ }^{33}$.

33 Estas votaciones (números 216 y 217) registraron 174 y 172 votos a favor de las respectivas enmiendas, y 160 en contra. Del análisis del escrutinio resulta que votaron a favor todos los senadores de la izquierda (24 del Grupo Comunista, Republicano, Ciudadano y de Senadores del Partido de la Izquierda; así como 116 socialistas), y algunos otros de diferentes grupos del centro 
b.2.2. Así las cosas, la mayoría presidencial-parlamentaria constituida en torno a los grupos UMP y UC se vio obligada a reaccionar, cosa que hizo al día siguiente, durante la sesión del 3 de junio, recurriendo a un mecanismo parlamentario peculiar.

En efecto, en este momento el Gobierno solicitó que se llevase a cabo una segunda deliberación y votación sobre aquellos extremos del proyecto enmendados el día anterior, y específicamente sobre la decisión de mantener el Defensor de los niños como figura autónoma, con todos los preceptos en que ello se reflejaba. Esta solicitud, formalmente indiscutida e indiscutible ${ }^{34}$, dio lugar a un enconado debate sobre su significado, enfrentándose básicamente dos posturas:

- Por un lado, los partidarios de la devolución (la mayoría que apoyaba al Gobierno) entendía que esta solicitud era normalmente utilizada para corregir errores como la ausencia de senadores que desvirtuaba el equilibrio político de la Cámara. En consecuencia, aducían que esa utilización habitual comportaba un resultado injusto, favoreciendo a los ausentes ("haciendo triunfar a los ausentes sobre los presentes", en la gráfica expresión empleada por uno de los participantes en el debate); por el contrario, en este caso se trataría de rectificar una decisión habida cuenta de que la mayoría había "tomado nota" de la existencia de dificultades, comprometiéndose a llegar a soluciones consensuadas.

- Por otro, los adversarios (la oposición, partidaria de mantener el Defensor de los niños y, por tanto, de no revisar la primera decisión del Senado) estimaban que esta utilización "forzada" de una votación en la que no había habido ningún error (dado que la Cámara se había expresado con claridad, por una mayoría holgada y tras un debate profundo), suponía un "desprecio político" al Parlamento, en tanto venía a extraer las consecuencias de diversos contactos celebrados, en esa misma mañana, fuera del mismo, con representantes de otras instituciones (Presidencia de la República, Gobierno), que habían logrado convencer a los parlamentarios "rebeldes" de la mayoría, hasta hacerles cambiar de posición ${ }^{35}$.

b.2.3. Finalmente, reagrupadas las filas, la Cámara aceptó la segunda deliberación (devolución a la Comisión) por 184 votos frente a 157. Este re-

y la derecha (2 del Grupo Rassemblement Démocratique et Social Européen, 22 de Unión Centrista, entre 8 y 10 del grupo UMP). En contra se pronunciaron 139 de la UMP, 15 del RDSE y 6 no inscritos. Además, se abstuvieron (o no participaron en la votación) 7 senadores centristas, 1 no inscrito, y alguno de la UMP (1 y 3 , respectivamente).

$34 \mathrm{El}$ artículo 43.4 del Reglamento del Senado prevé que, antes de la votación final sobre el conjunto de un texto, la Cámara puede decidir devolver la totalidad del texto, o parte del mismo, a la Comisión para una segunda deliberación, a condición de que la demanda de devolución haya sido formulada o aceptada por el Gobierno.

35 El debate puede consultarse en el Diario de Sesiones del Senado (Compte rendu intégral des débats), sesión del 3 de junio, páginas 4448 y siguientes. 
sultado provocó el que la oposición anunciase su intención de abandonar los trabajos e, inmediatamente después - de hecho, el mismo día- el nuevo texto, ya corregido en el sentido querido por la mayoría presidencial y parlamentaria, se sometió nuevamente al Pleno de la Cámara, que lo aprobó por 174 votos favorables (146 UMP y 28 UC) y ninguno en contra (dada la ausencia de los senadores comunistas, socialistas y del Grupo RDSE). Tan sólo se abstuvieron un senador UMP (autor de una de las enmiendas rectificadas) y otra centrista.

b.3) De esta forma, el texto finalmente aprobado por el Senado, y remitido a la Asamblea Nacional, otorga cierta preeminencia —al menos, nominativa, ya que se mantiene la integración institucional, y por tanto las modificaciones afectan esencialmente a la estructura orgánica del Défenseur des droits - al Defensor de los niños, que se diferencia claramente de los otros dos "adjuntos" que siguen previéndose en materia de deontología en materia de seguridad, y de lucha contra las discriminaciones.

En definitiva, esa preeminencia se traduce en que, según el nuevo artículo $11 \mathrm{~A}$, apartado segundo, el Defensor de los niños y los otros dos adjuntos serán nombrados por el Primer Ministro, a propuesta del Defensor de los derechos y previo informe de las Comisiones parlamentarias competentes. Finalmente, se elimina el "colegio" consultivo en materia de defensa de los derechos del niño.

\section{A MODO DE CONCLUSIÓN... PROVISIONAL}

Obviamente, y a la vista de cuanto hasta aquí se ha expuesto, resulta difícil predecir cuál va a ser la evolución de los acontecimientos en torno a la articulación de esta figura. La cual, no cabe olvidarlo, resulta por lo demás constitucionalmente necesaria, pese a todas las dificultades y polémicas que puedan surgir al hilo de la misma. En definitiva, sólo el tiempo nos dirá cómo - y cuándo- esa articulación tiene lugar, algo que esperamos poder registrar en crónicas futuras.

\section{TITLE: The difficult joint of a new institution: the French Ombudsman}

ABSTRACT: In 2008, the amended 1958 French Constitution foresaw the establishment of a new organ, the Defender of Rights, somehow inspired by the Spanish experience of the Defender of the People, and whose specific features had to be precised by an organic law. Two years after, the constitutional mandate has not been implemented yet, and the debate about the new body - and its relations with other bodies performing similar functions in the field of protection of rightsmakes it difficult to predict how and when the new organ will begin to work.

RESUMEN: En 2008, la reforma constitucional francesa estableció un nuevo órgano, el Defensor de Derechos, de alguna forma inspirado en la experiencia española del Defensor, cuyos rasgos específicos tienen que ser desarrollados por ley orgánica. Dos años después, el mandato cons- 
titucional no ha sido desarrollado todavia y el debate sobre el nuevo cuerpo $-y$ sus relaciones con otras instituciones con actividades similares- hacen difícil de prever cuando comenzará a operar el nuevo instituto creado.

KeYwords: French Constitution. Ombudsman.

Palabras clave: Constitución Francesa. Defensor del Pueblo.

FECHA DE RECEPCIÓN: 09.07.2010. FeCHA DE ACEPTACIÓN: 28.07.2010. 